\title{
The perception of rate in spoken and sign languages
}

\author{
FRANÇOIS GROSJEAN \\ Northeastern University, Boston, Massachusetts 02115
}

\begin{abstract}
The methods of magnitude production and estimation were used to scale the perception of signing rate by signers and observers. As in the case of voice level and speech rate, the autophonic scale of signing rate has a slope greater than unity and is steeper than the correspond. ing extraphonic scale; the obtained exponents of the two power functions for signing are, respectively, 2.66 and 1.56. When English-speaking subjects estimated their own rate of reading of the translated version of the signed passage, they produced an autophonic reading scale quite similar to that for signing (exponent of 2.51 ), but when they made magnitude estimations of English rates covering the same range of rates as the signed passage, the exponent of the extraphonic reading scale was significantly larger (1.89). This was also the case when French subjects estimated French reading rates. The difference between extraphonic signing and reading scales was confirmed by subjects who knew no Sign Language or French; their results appear to indicate, in addition, that the processes involved in extraphonic perception of rate are purely acoustic (speech) or visual (sign) and do not require, as one could have thought, deeper linguistic operations.
\end{abstract}

Changes in the rate of speaking appear larger than they really are both to listeners and to speakers. When a speaker doubles his reading rate, which he does primarily by subtracting pauses at strategic syntactic locations, he perceives a sixfold increase and his listener perceives about a threefold increase. In other words, the functions relating apparent rate to physical rate are power functions with exponents of 2.6 and 1.6, respectively (Lane \& Grosjean, 1973). This disparity between the perception of spoken rate and heard rate (autophonic and extraphonic rate) shows that the speaker does not rely exclusively on his hearing in judging his rate; he must also be guided by other cues such as tactile and proprioceptive feedback.

The extraphonic scale of speaking rate has been the object of further investigation: Grosjean and Lass (1977) showed that the slope of the scale remains relatively invariant across passages, languages (English and French), and methods of altering rate, but can be affected by changes in the range of the stimuli presented. Next, Grosjean and Lane (1976) showed how the listener combines the components of the rate of speaking (that is, articulation rate and the

This research was supported in part by Grant 1 R03 MH 2813301, Department of Health, Education and Welfare, Grant 7682530 , National Science Foundation, and a Fulbright-Hays award. The author would like particularly to thank A. McIntyre for her assistance in making the videotapes and $\mathrm{H}$. Lane, $\mathrm{B}$. Scharf, and J. Miller for their useful comments and criticisms. Requests for reprints should be sent to François Grosjean, Department of Psychology, Northeastern University, 360 Huntington Avenue, Boston, Massachusetts 02115. number and duration of pauses) into a global impression of speech rate. They present a model based on direct scaling and linear regression that provides for a trading relation between articulation rate and pause rate in which the former is much more influential in determining the listener's perception of speech rate.

Research on the perception and production of speech rate has been conducted so far solely with oral-aural linguistics codes (mainly English and French), and virtually nothing is known about timing in manual-visual codes (sign languages) such as those used by deaf persons. The Sign Language used by deaf communities in the United States since the 19th century, known as American Sign Language (ASL), has only recently become the object of systematic research by linguists and psychologists (Battison, 1974; Bellugi \& Fischer, 1972; Frishberg, 1975; Grosjean \& Lane, 1977; Lane, Boyes-Braem, \& Bellugi, 1976; Stokoe, 1960; Woodward, 1974). They have shown that ASL is a systematic natural form of symbolical communication among a stable community of users and that it has the degree of regularity and structure required of a fully developed language. ASL is not some form of English on the hands; it is a different language with different structural principles. For example, a sign in ASL seems to be composed of at least four distinct parameters: shape of the hand, location of the hand, orientation of the palm, and movement of the hand. To illustrate this, the sign for the concept GIRL is made with the hand in a fist, the thumb tip brushing down the lower cheek. Experimental evidence that these 
parameters are perceptually real for signers was obtained in a short-term memory study for signs by Bellugi, Klima, and Siple (1975); they showed that a significant number of errors were formational rather than semantic confusions. That the structure of ASL is influenced by the visual mode of the language is intriguing for researchers who are interested in how deeply language structures are rooted in the human being-as deeply as the cognitive structures and processes of the human mind or as superficially as the mode in which the language is communicated?

In the present study, we will ask two types of questions. On the one hand, questions pertaining to the nature of the signer's and observer's perception of signing rate: Does apparent signing rate grow as a power of physical rate, both for the observer and signer? Does the signer's perception of his own rate (the autophonic scale) have a slope greater than 1 and is it steeper than the corresponding extraphonic scale, as is the case for voice level (Lane, Catania, \& Stevens, 1961) and speech rate (Lane \& Grosjean, 1973)? And how different are the signing scales from corresponding speech scales? On the other hand, we will ask questions pertaining to the sensory system mediating these scales: Is the perception of both speech rate and signing rate mediated by the same sensory system? And is linguistic decoding required in extraphonic judgments of rate? We will answer this last question by obtaining extraphonic scales of signing rates and French speaking rates from subjects who know neither language. The extent to which their scales differ from those of native speakers will be an indication of whether some amount of linguistic decoding takes place in the listener's perception of rate, the nonlinguistic "baseline" functions being those of the nonnative subjects.

\section{METHOD}

Subjects

A total of 97 subjects, native "speakers" of English, French, or ASL took part in seven experiments on autophonic and extraphonic rate. Their characteristics (native language, academic level, age range, and number per experiment) are presented in Table 1. No subject took part in more than one experiment.

\section{Materials}

Magnitude productions of signing rate were obtained by asking deaf subjects to sign the Goldilocks passage':

LONG-TIME-AGO GIRL SMALL DECIDE WALK IN WOODS INTO WOODS SEE HOUSE INTO VERY HUNGRY THEN SIT-DOWN SEE BOWL BIG-BOWL EAT DON'T LIKE COLD MOVE-ON BOWL HOT REALLY DON'T LIKE IT MOVE-ON SMALLEST BOWL EAT-EAT PERFECT HUMM EAT ALL-GONE THEN SIT THREE DIFFERENT CHAIRS SAME THING HAPPEN ONE HARD ONE SOFT ONE PERFECT

The idiomatic English translation of the above passage was then used to obtain magnitude productions of English speech rate from hearing subjects:

\begin{abstract}
A long time ago, a little girl decided to take a walk in the woods. In the woods she saw a house and went in. She was very hungry, so she sat down. She saw a big bowl and began to eat. She didn't like it because it was too cold. She went to the next bowl. This one was too hot and she really didn't like it. Then she went to the smallest bowl and ate and ate. It was good, really good, and so she ate it all up. Then she saw three different chairs and sat on each of them. One was too hard, one was too soft, and one was just right.
\end{abstract}

Magnitude estimations of rate in English and ASL were also based on these two passages. Five reading rates were extracted from one subject's magnitude productions $(139,184,223,316$, $387 \mathrm{wpm}$ ) and were used as the English stimuli, while four signing rates $(51,79,94,140$ signs per minute) covering approximately the same range as the English reading rates (respectively, 2.78:1 and 2.75:1) were likewise taken from a signer's magnitude productions and used as the sign stimuli. ${ }^{2}$ Magnitude estima-

Table 1

Subjects in the Speech and Sign Experiments

\begin{tabular}{|c|c|c|c|c|c|c|}
\hline $\begin{array}{c}\text { Type of } \\
\text { Perception }\end{array}$ & $\begin{array}{l}\text { Language } \\
\text { Presented or } \\
\text { Produced }\end{array}$ & $\begin{array}{c}\text { No. of } \\
\text { Subjects }\end{array}$ & $\begin{array}{c}\text { Subjects' First } \\
\text { Language }\end{array}$ & Characteristics & $\begin{array}{l}\text { Academic } \\
\text { Level }\end{array}$ & $\begin{array}{l}\text { Age } \\
\text { Range }\end{array}$ \\
\hline \multirow{2}{*}{ Autophonic } & ASL & 22 & ASL & Congenitally deaf & $\begin{array}{l}\text { End of High School } \\
\text { and Undergraduate }\end{array}$ & $17-27$ \\
\hline & English & 11 & English & $\begin{array}{l}\text { No reported speech } \\
\text { or hearing defects }\end{array}$ & Undergraduate & $18-23$ \\
\hline \multirow{5}{*}{ Extraphonic } & ASL & 10 & ASL & Congenitally deaf & $\begin{array}{l}\text { End of High School } \\
\text { and Undergraduate }\end{array}$ & $17-25$ \\
\hline & ASL & 10 & $\begin{array}{l}\text { English } \\
\text { (no ASL) }\end{array}$ & $\begin{array}{l}\text { No reported speech } \\
\text { or hearing defects }\end{array}$ & Undergraduate & $18-23$ \\
\hline & English & 10 & English & $\begin{array}{l}\text { No reported speech } \\
\text { or hearing defects }\end{array}$ & Undergraduate & $18-24$ \\
\hline & French & 22 & French & $\begin{array}{l}\text { No reported speech } \\
\text { or hearing defects }\end{array}$ & Undergraduate & $18-30$ \\
\hline & French & 12 & $\begin{array}{l}\text { English } \\
\text { (no French) }\end{array}$ & $\begin{array}{l}\text { No reported speech } \\
\text { or hearing defects }\end{array}$ & Undergraduate & $18-24$ \\
\hline
\end{tabular}


tions of rate in French were based on the reading rates employed by Grosjean and Lass (1977) in their study: 116, 158, 183, 234, 271 wpm. The passage was the idiomatic translation of the Pop Fan passage (Lane \& Grosjean, 1973):

A vrai dire, je suis jeune de quinze ans à peu près normal, ni un cas psychologique sérieux, ni un gars au-dessus des autres. J'écoute Radio Luxembourg, je laisse pousser mes cheveux pour être à la mode, et je porte des cols roulés, mais je ne pense pas être un véritable passionné de musique pop.

\section{Procedure}

The method of magnitude production was used to determine the autophonic scale of rate in English and Sign (Lane \& Grosjean, 1973). The subject was asked to read or sign the experimental passage at normal rate. To the apparent rate of this production, the Experimenter assigned the numerical value 10. A series of values $(2.5,5,10,20$, and 30$)$ was then named in irregular order, four times each, and the speaker or signer responded to each value by reading or signing the passage with a proportionate apparent rate. The English passage was typewritten double space. The sign passage was printed in English glosses on a $70 \times 55 \mathrm{~cm}$ panel; the letters were $12 \mathrm{~mm}$ high. The panel had a $9 \times 9 \mathrm{~cm}$ hole at its center so it could be slipped over the lens of the video camera, located $2 \mathrm{~m}$ from the subject. The speech productions were taperecorded (Crown SS800) in an audiometric room, and the sign productions were video-recorded (Sony AVC 3250 S and VTR 3650) in a television studio. Both speech and sign passages were then timed using a chronoscope (Standard Timer S1) to an accuracy of $1 \%$ or better.

The method of magnitude estimation was used to measure extraphonic perception of speech and signing rate (English, French, and ASL). The English played a recording of the experimental passage read or signed at moderate rate $(223$ and $183 \mathrm{wpm}$ for English and French and $79 \mathrm{spm}$ for Sign); to this standard, he assigned the numerical value 10 . Next, he played 20 recordings of the speech passage ( 16 recordings of the Sign passage), and the listener or observer assigned to each a number proportional to its apparent rate. In all, five rates of reading in English and French and four rates of signing were presented four times in irregular order. Magnitude estimations were obtained from the subjects in group sessions. The signing rates were presented by means of a video-recorder (Sony VTR 3650) and monitor (Sony AVC 3250S). The English and French rates were presented, respectively, by means of a tape recorder (Tandberg $1600 \mathrm{X}$ ) and loudspeaker (Acoustic Research AR-4x) and a tape recorder with an incorporated loudspeaker (Opelem 2M70).

\section{RESULTS AND DISCUSSION}

\section{Autophonic Perception of Speech Rate and Signing Rate}

The autophonic scales of perception of rate by

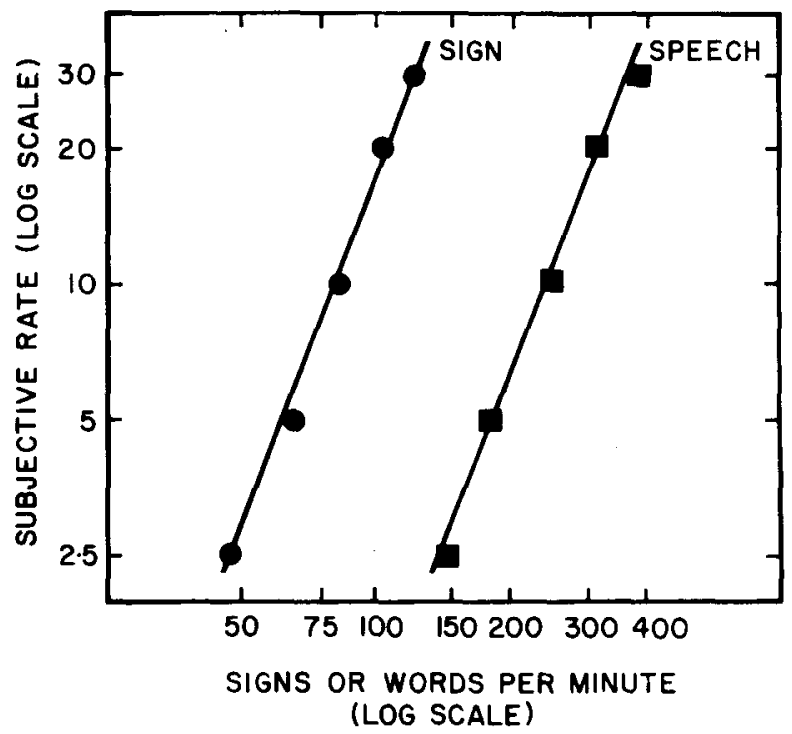

Figure 1. Autophonic scales of signing and speaking rates. Each circle is the geometric mean of 88 signing productions, 4 by each of 22 signers. Each square is the geometric mean of 44 speech productions, 4 by each of 11 speakers.

speakers and signers are plotted in Figure 1. The results are well fit by straight lines in $\log -\log$ coordinates. Consequently, apparent autophonic signing rate, like apparent speaking rate, grows as a power of physical rate. The exponents obtained are 2.51 for speech [Lane \& Grosjean (1973). report a slope of 2.6] and 2.66 for sign; the difference between the two slopes is not significant $(t=0.19)$. (Table 2 presents the mean and SD of the slopes of individual subjects.) Thus, autophonic signing rate joins the other autophonic speech scales, indicating that the sensory mechanisms mediating the speaker's or the signer's perception of his own output amplify constant stimulus ratios into much larger constant subjective ratios; when either a speaker or signer doubles his production rate, he will perceive about a sixfold increase. These results suggest that a common mechanism possibly involving proprioception may mediate both types of autophonic rate

Table 2

Means and Standard Deviations of the Slopes Relating Numerical Estimates to Speech Rate (English and French) and Signing Rate (ASL)

\begin{tabular}{|c|c|c|c|c|c|}
\hline $\begin{array}{c}\text { Type of } \\
\text { Perception }\end{array}$ & $\begin{array}{c}\text { Language } \\
\text { Presented or } \\
\text { Produced }\end{array}$ & Subjects & $\begin{array}{l}\text { Range } \\
\text { Ratio* }\end{array}$ & $\begin{array}{c}\text { Mean of } \\
\text { Slopes }\end{array}$ & $\mathrm{SD}$ \\
\hline Autophonic & $\begin{array}{l}\text { ASL } \\
\text { English }\end{array}$ & $\begin{array}{l}\text { Native Sign } \\
\text { Native English }\end{array}$ & $\begin{array}{l}2.60: 1 \\
2.71: 1\end{array}$ & $\begin{array}{l}2.66 \\
2.51\end{array}$ & $\begin{array}{l}1.05 \\
1.28\end{array}$ \\
\hline Extraphonic & $\begin{array}{l}\text { ASL } \\
\text { ASL } \\
\text { English } \\
\text { French } \\
\text { French }\end{array}$ & $\begin{array}{l}\text { Native Sign } \\
\text { No Sign } \\
\text { Native English } \\
\text { Native French } \\
\text { No French }\end{array}$ & $\begin{array}{l}2.75: 1 \\
2.75: 1 \\
2.78: 1 \\
2.34: 1 \\
2.34: 1\end{array}$ & $\begin{array}{l}1.56 \\
1.49 \\
1.89 \\
1.82 \\
1.92\end{array}$ & $\begin{array}{l}.28 \\
.25 \\
.24 \\
.53 \\
.32\end{array}$ \\
\hline
\end{tabular}


judgments. Thus, whether the movable articulators are, for example, the tongue, the lips, and the jaw or the hands and arms, similar autophonic sensations will guide signers and speakers to produce similar changes in production rate.

\section{Extraphonic Perception of Speech Rate and Sign- ing Rate}

The extraphonic perception of signing rate is described in Figure 2 (unfilled circles). The magnitude estimates are well fit by a straight line in a log$\log$ coordinates with slope 1.56 . (The mean and SD of the individual slopes are presented in Table 2.) We conclude that extraphonic signing rate also grows as a power of physical rate but more slowly than autophonic signing rate. When a signer doubles his signing rate, he perceives a sixfold increase, whereas an observer perceives about a threefold increase. The extraphonic scale of signing rate is validated by the scale obtained from subjects who know no Sign Language whatsoever; their estimates are also well fit by a straight line in log-log coordinates (unfilled squares in Figure 2) with a slope of 1.49. The difference between the two slopes is not significant $(t=$ $.59)$.

These results are almost identical to those reported by Lane and Grosjean (1973) for speech, where the listener's apparent rate grew as the 1.5 power of physical rate. However, reading rate covered a 3.9:1 range in that study, whereas signing rate covers only a 2.75:1 range here. As Grosjean and Lass (1977) have shown that the intramodal range effect (Teghtsoonian, 1973) is also applicable to the speech rate continuum, a comparable range of rates was used to compare the extraphonic scales of signing and speech rates. The function obtained for apparent extraphonic reading rate using the English version of the Goldilocks passage is shown in Figure 2 (filled triangles). With an almost identical range of rates (2.78:1 as compared to $2.75: 1$ for the signing rates), the exponent obtained, 1.89 , is significantly different from those reported above for signing rate for fluent (1.56) and naive (1.49) observers $(t=2.64$ and $3.45, \mathrm{p}<.01$, respectively). We can conclude therefore that with an equal range of rates, the extraphonic perception of speaking rate and of signing rate is different: 1.9 vs. 1.5 . This divergence is confirmed by French native speakers and subjects knowing no French in their estimates of reading rate of the French Pop Fan passage, where rates covered a 2.34:1 range. The exponents obtained (filled circles for the native speakers and filled squares for "naive" subjects in Figure 2) are 1.82 and 1.92, respectively. Thus, when a signer or a reader doubles his rate, an observer will perceive a threefold increase in the signer's production whereas a listener will perceive almost a fourfold increase in the reader's change of rate.

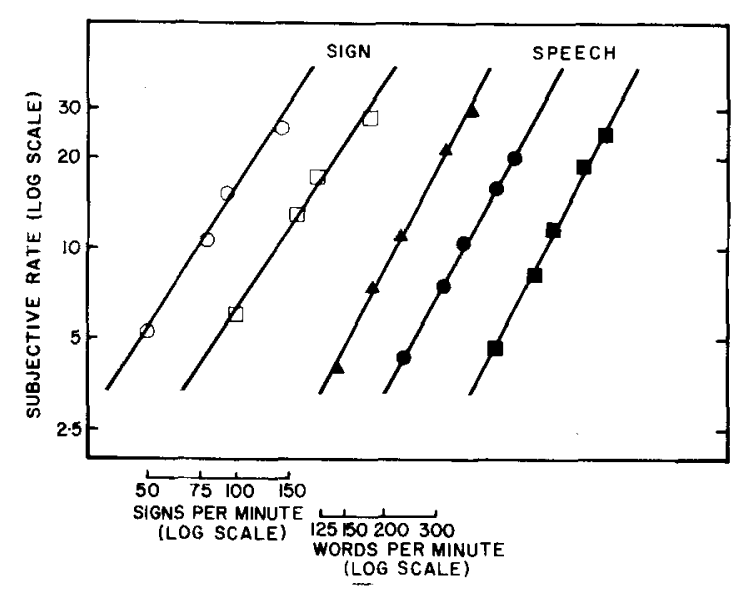

Figure 2. Extraphonic scales of signing and speaking rates. Each unfilled circle is the geometric mean of 40 magnitude estimations of signing rate, 4 by each of 10 native signers, and each unfilled square is the geometric mean of $\mathbf{4 0}$ magnitude estimations of signing rate, 4 by each of 10 observers with no knowledge of Sign. For clarity, the two sign functions are separated by a 50 -spm interval. Each filled triangle is the geometric mean of 40 magnitude estimations of English speaking rate, $4 \mathrm{by}$ each of 10 native speakers of English. Each filled circle is the geometric mean of 88 magnitude estimations of French speaking rate, 4 by each of 22 native speakers of French, and each filled square is the geometric mean of $\mathbf{4 8}$ magnitude estimations of French speaking rate, 4 by each of 12 listeners with no knowledge of French. For clarity, the three speech functions are separated by a 100-wpm interval.

In an attempt to understand this difference in extraphonic scales, we should note first of all that linguistic decoding does not seem to be involved in judgments of change in signing and reading rate; observers who have no knowledge of Sign Language and listeners who know no French behave, on this task, exactly like native speakers of the two languages. Both observers and listeners would appear to base themselves solely on the auditory or visual stimuli when asked to judge change of rate in language production; such factors as how fast the hands and arms are moving and how often and for how long they stop will be of primary importance to the observer, whereas how many syllable peaks occur per second and what the duration and frequency of pauses are will be the bases of the listener's judgment (Grosjean \& Lane, 1976). The processes involved, therefore, are purely acoustic and visual and do not require, as one could have thought, deeper linguistic operations. This finding will need further investigation, however, as the actual estimates made by observers who had no knowledge of Sign Language and listeners who knew no French were usually higher than those of the native speakers of the two languages (see Figure 2). For example, the mean rate estimate for the sign passage presented at $79 \mathrm{spm}$ was 10.77 for native sign observers but 13.34 for 
naive observers $(t=2.86, p<.01)$ and the mean rate estimate for the French passage presented at $183 \mathrm{wpm}$ was 10.59 for native French listeners and 12.08 for naive listeners $(t=1.84, p<.05)$. Thus, change of rate is perceived in an identical manner by "naive" and native speakers (and thus the slopes are identical), but actual rates are usually overestimated by the former group.

An examination of previous studies that used repetition rate as the independent variable does not throw much light on the reason observers and listeners perceive rate of signing and speaking differently. In two studies on visual and auditory perception of number, Cheatham and White $(1952,1954)$ presented subjects with a varying number of pulses and flashes and had them report the heard or observed number. An examination of the results at the slowest rate of presentation $(10 / \mathrm{sec})$ shows differing slopes for perceived number of flashes and pulses. In both cases, subjects underestimate the number presented but the slope for pulses is closer to unity than that for flashes (slopes of 0.92 and 0.41 in linear coordinates were calculated from the data published by the authors). Stevens and Shickman (1959) also presented visual flashes and auditory pulses at varying rates, but asked subjects to give magnitude estimations of the repetition rates instead of asking for perceived numbers. They report identical slopes for the two types of rate with an exponent close to unity. The range of rates used (a 40:1 range) may explain the relatively shallow slope [both Poulton (1968) and Teghtsoonian (1973) have shown that as the range of a stimulus increases, the exponent of the power law decreases]. However, the similarity of the two exponents remains unexplained and inconsistent with our finding for extraphonic perception of signing and speaking rates.

The main difference between these two studies and our study is probably in the nature of the stimuli used. Unlike the very regular and simple on-off repetition pattern employed by Cheatham and White (1952, 1954) and Stevens and Shickman (1959), the visual and auditory language pattern of ASL and English and French is considerably more complex. Such common factors to speech and sign as pause frequency and duration, articulation rate and its fluctuation within the passages, and stress distribution are all combined by the listener and observer to produce a global impression of production rate that differs, as we have seen, for speech and sign. It is only by manipulating such factors singly and in combination that one could show how observers and listeners start diverging in their estimation of rate as the stimulus pattern progresses from a simple on-off configuration, as in Stevens and Shickman, to a more complex arrangement characteristic of the stream of speech and sign, as in the present study.

\section{REFERENCES}

Battison, R. Phonological deletion in American Sign Language. Sign Language Studies, 1974, 5. 1-19.

Bellugi, U. \& \& Fischer, S. A comparison of Sign Language and spoken language: Rate and grammatical mechanisms. Cognition. 1972, 1. 173-200.

Bellugi. U., Klima, E., \& Siple, P. Remembering in signs. Cognition, 1975, 3, 93-125.

Cheatham, P. G., \& White, C. T. Temporal numerosity: I. Perceived number as a function of tlash number and rate. Journal of Experimental Psychology, 1952, 44, 447-451.

Cheatham, P. G., \& White. C. T. Temporal numerosity: III. Auditory perception of number. Joumal of Experimental Psychology, 1954, 47, 425-428.

FrishberG, N. Arbitrariness and iconicity: Historical change in American Sign Language. Language, 1975, 51, 676-719.

Grosjean, F. A study of timing in a manual and a spoken language: American Sign Language and English. Journal of Psycholinguistic Research. 1977. in press.

Grosiean. F., \& LANE, H. How the listener integrates the components of speaking rate. Journal of Experimental Psychology: Human Perception and Performance, 1976, 2. 538-543.

Grosjean, F., \& Lane, H. Pauses and syntax in American Sign Language. Cognition, 1977, 5, 101-117.

Grosjean, F., \& Lass, N. Some factors affecting the listener's perception of reading rate in English and French. Language and Speech, 1977, in press.

Lane, H.. Boyes-Braem, P.. \& Bellugi, U. Preliminaries to a distinctive feature analysis of handshapes in American Sign Language. Cognitive Psychology, 1976, 8, 263-289.

Lane, H., Catania, A., \& Stevens, S. S. Voice level: Autophonic scale, perceived loudness and effects of sidetone. Journal of the Acoustical Society of A merica. 1961, 33, 160-167.

Lane. H., \& Grosjean, F. Perception of reading rate by listeners and speakers. Journal of Experimental Psychology. $1973,97,141-147$.

Poulton, E. C. The new psychophysics: Six models for magnitude estimation. Psychological Bulletin, 1968, 69, 1-19.

Stevens, J. C., \& Shickman, G. M. The perception of repetition rate. Journal of Experimental Psychology, 1959, 58, 433-440.

Stоког. W. C. Sign Language structure: An outline of the visual communication system of the American deaf. Studies in Linguistics: Occasional Papers, 1960. No. 8.

Stokoe, W. C., Casterline, D. C., \& Croneberg, C. G. $A$ dictionary of American Sign Language. Washington, D.C: Gallaudet College Press, 1965.

Teghtsoonian, R. Range effects in psychological scaling and a revision of Stevens' law. American Journal of Psychology, 1973, 86, 3-27.

WOODWARD, J. C. Implication variation in American Sign Language: Negative incorporation. Sign Language Studies, 1974, 5. 20-30.

\section{NOTES}

1. This passage was originally used by Grosjean and Lane (1977) and was obtained by asking an English-ASL bilingual to sign a story that she learned as a young child from her deaf parents. A video recording was made (Sony AVC 3250 S and VTR 3650), and the first part of the story was transcribed literally into English, giving a 52-sign passage. Hyphenated glosses correspond to a single sign. It is important to recognize that the ASL passage reported here is not translated into English; rather than use a transcription system (e.g., Stokoe, Casterline, \& Croneberg, 1965), we have transliterated the passage by substituting an English gloss for each sign. 
2. Bellugi and Fischer (1972) and Grosjean (1977) have shown that a signer articulates more slowly than a speaker; the latter produces about 2.8 words in the time it takes a signer to produce one sign. This has no effect on the number of propositions per minute, however; Bellugi and Fischer (1972) have indeed shown that ASL-English bilinguals take the same amount of time to tell a story in ASL as in English and produce the same number of propositions in the two languages.

(Received for publication January 24, 1977; revision accepted June 30,1977 .) 